\title{
Crash Analysis of Front under Run Protection Device using Finite Element Analysis
}

\author{
Santosh Pandimukkula.,Venkata Narayana Yenugula \\ ${ }^{1}$ (Mechanical Departmen,Sreenidhi Institute of Science and Technology/JNTUH, INDIA) \\ ${ }^{2}$ (Mechanical Departmen,Sreenidhi Institute of Science and Technology/JNTUH, INDIA)
}

\begin{abstract}
Under-running of passenger vehicles is one of the important parameters to be considered during design and development of truck chassis. Front Under-run Protection Device (FUPD) plays an important role in avoiding under-running of vehicles from front side of a truck. An explicit finite element software Altair Radio's is used in FUPD analysis for impact loading. The deformation of FUPD bar and plastic strains in FUPD components are determined in the impact analysis for predicting failure of the system to meet the compliance requirements as per IS 14812-2005. Additionally, failure analysis of the FUPD attachment points with chassis is determined. Physical testing can be reduced significantly with this approach which ultimately reduces the total cycle time as well as the cost involved in product development.
\end{abstract}

Keywords: Front Under-Run Protection Device (FUPD), Chassis design, impact loading, Altair Radio's

\section{INTRODUCTION}

In head-on collisions of bonnet-type cars (sedans, wagons, hatchbacks, etc., here after referred to simply as cars) and heavy trucks, the car often under runs the front of the truck, and the car crew received the serious or fatal injuries. The crash safety performance of the car depends on the way its structural parts interact with the structural parts of the truck. FUPD equipment that prevents the car from under running the truck is obligatory in India. The required strength and ground clearance of FUPDs are specified in the relevant regulations used in India. Accidents between cars and trucks are among the most fatal accidents because of the car under running. This phenomenon leads to serious and fatal injuries for car occupants because of intrusion of the car structure into the passenger compartment.

This has led to the development of test procedure for energy-absorbing front under run protection systems for trucks. There is a summary of accident analysis of several European countries, where we can read that of the 48000 fatally injured people in road traffic accidents in 1992, 13000 people were killed in accident with trucks involved, about 7000 were car occupants and 4200 of them were killed in car-to-truck frontal collisions.

It is very common incident that during the accident a passenger vehicle going under the heavy commercial vehicle either from rear, front or side. During collision, there is a risk that the passenger vehicle will penetrate under (run under) the front or rear part of the truck and thus there are great chances of fatal injuries to the occupants of the passenger car. The design and the strength of the Front Under-run Protection Device (FUPD) should be such that it should take the impact load and avoid the under running of the passenger vehicle from the front of the heavy commercial vehicle. Physical testing is done with 5 impactors with specific load and sequence; hit the FUPD to evaluate its strength. This scenario is replicated using Finite Element (FE) solvers like Altair Radio's. The load taken by the FUPD is evaluated using reaction forces. This virtual validation is important for cost saving in the tooling, repetitive testing of the vehicle and cost involved in the same.

The Government of India felt the need for a permanent agency to expedite the publication of standards and development of test facilities in parallel when the work on the preparation of the standards is going on, as the development of improved safety critical parts can be undertaken only after the publication of the standard and commissioning of test facilities. To this end, the Ministry of Surface Transport (MOST) has constituted a permanent Automotive Industry Standards Committee (AISC) vide order No.RT-11028/11/97-MVL dated September 15, 1997. The standards prepared by AISC will be approved by the permanent CMVR Technical Standing Committee (CTSC). After approval, the Automotive Research Association of India, (ARAI), Pune, being the Secretariat of the AIS Committee, has published this standard. For better dissemination of this information ARAI may publish this document on their web site.

In Indian vehicles FUPD, still it is not implemented. By this analysis will know that how it can reduce passenger life while impacting to car, pole..Etc. FUPD is designed with the help of European standard dimensions and then will apply the initial velocity from front side and check the strength of the FUPD, if it safe then this thesis is successfully projected. It's a trial and error process.

The strategy in selecting a test procedure is to identify tests that have the potential to improve the crash protection provided across a broad range of real-world impact conditions. The crash test conditions, e.g., impact 
speed, impact angle, test devices and configurations, must be carefully selected to be representative, as much as possible, of the real car to truck crashes.

FUPD's installed in the trucks. At the same time, they provide information for the properly definition of the evaluation tests to be proposed. The aim of the next task of the project is to propose guidelines for the definition of a test procedure less complicated, easier and unambiguous than car to truck crash tests. This test should be carried out without vehicles, to evaluate the behavior of the FUPD independently of the truck attached to, and of the impacting car considered.

To check the effectiveness of equipping trucks with FUPDs, head-on car-truck collision tests were conducted. Trucks with and without FUPDs were used in these tests. The same car type and collision speeds were used in each test.

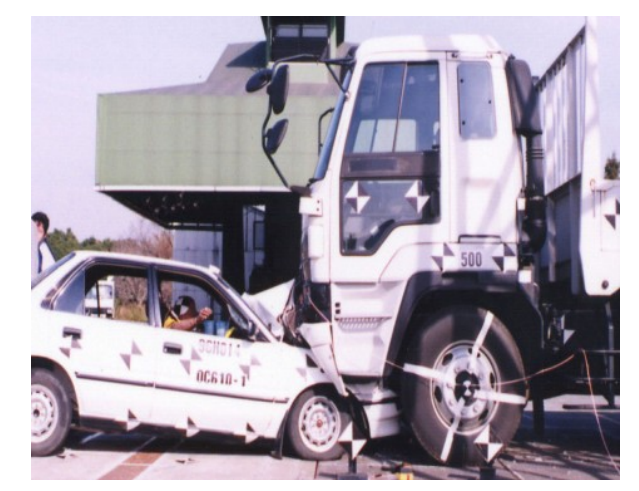

\section{LITERATURE REVIEW}

Truck accidents represent a significant factor in the overall road accident scene. EEVC Working Group 14 started in 1994 a research programmed for defining the requirements of energy absorbing front under run protection systems for truck, and for the development of a test procedure for these devices.

In March 1995, the Working Group 14 concluded a statistics analysis of accident data involving car-totruck frontal collisions in most countries of the European Community. The possible configurations of the test are discussed. This includes a proposal for the definition of the target and bullet vehicles to be used in dynamic tests, and a first approximation to the type of parameters to be measured.

In 1997 by Analyzing the European problem (1997), trucks with a gross vehicle weight of more than 3.5 tones are involved in around $20 \%$ of the fatal road accidents; and approximately $60 \%$ of these is car to truck accidents.

The overall objective of the project consists of developing a test procedure and performance standard for energy - absorbing front under run protection systems for trucks in order to reduce the injuries to passenger car occupants in frontal collisions. The Spanish partner in this working group is INSIA (University Institute for Automobile Research).

\section{Finite ELEMENT ModeLLING} analysis.

Design of FUPD is done with the help of NX8.0 software is used for designing the $3 \mathrm{~d}$ model for virtual

As per Indian rules and regulations this dimensions are little changed, approximate dimensions are took from 3.1.Nx8.0 software is used, in which starting from scratch will design FUPD.

GEOMETRICAL PARAMETERS

\begin{tabular}{|l|l|c|c|c|}
\hline PART NAME & $\frac{\text { LENGT }}{\text { H }}$ & $\frac{\text { WIDT }}{\text { H }}$ & $\frac{\text { HEIGH }}{\text { THICKN }}$ & $\frac{\text { THS }}{\text { ESS }}$ \\
\hline FUPD & 1479.35 & 203.43 & 109.79 & 1 \\
\hline $\begin{array}{l}\text { SUPPORTING } \\
\text { BRACKET }\end{array}$ & 99.26 & 0 & 179.70 & 1 \\
\hline $\begin{array}{l}\text { STAY } \\
\text { BRACKET }\end{array}$ & 173.58 & 0 & 353.91 & 1 \\
\hline L-BRACKET & 148.6 & 160.0 & 0 & 1 \\
\hline $\begin{array}{l}\text { CHASIS CROSS } \\
\text { MEMBER }\end{array}$ & 840.39 & 74.16 & 140.00 & 1 \\
\hline CHASIS & 867.18 & 123.42 & 150.00 & 1 \\
\hline
\end{tabular}

All Dimensions are in $\mathrm{mm}$. 


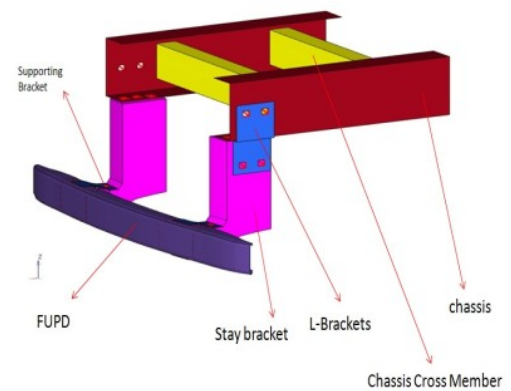

Importing 3d model into Altair Hyper Works software, by using Altair Radios Solver for doing crash analysis and for visualization of results Altair Hyper view for plotting the graph Altair Hyper Graph is used.

\section{Meshing}

After importing a model into Altair Hyper work we have to carry out the meshing, for this meshing element type is shell element, having the 5714 no of elements with size of the element is 10 .

\section{Crash Analysis}

For Crash analysis the boundary conditions are given to chassis, at the bottom portion of the chassis is fixed with rigid. And the load applied is $\mathrm{m}=800 \mathrm{Kg}$ with a velocity $\mathrm{v}=894 \mathrm{~m} / \mathrm{s}$ and the friction value is 0.1 given to the FUPD along its direction of motion.

Front under run Protection Device is tested for car occupant safety by performing Crash analysis by hitting the FUPD with certain velocity and analyzing its performance and changing design to improve the crash results.

\section{RESUltS AND DiscuSSION}

Altair Hyper view is a Post processing tool, which is highly robust and easy to learn tool. In which displacement, stresses and strain can be visualize.

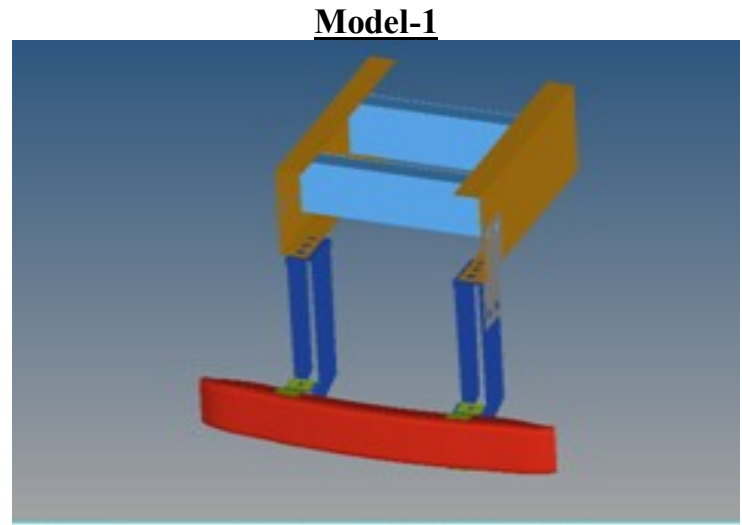

In this model the stay bracket is having the plates of thickness $1 \mathrm{~mm}$ without contact in between two surfaces i.e. hallow portion inside. And doing analysis for this model to check the model is safe or not.Vonmisses Stress
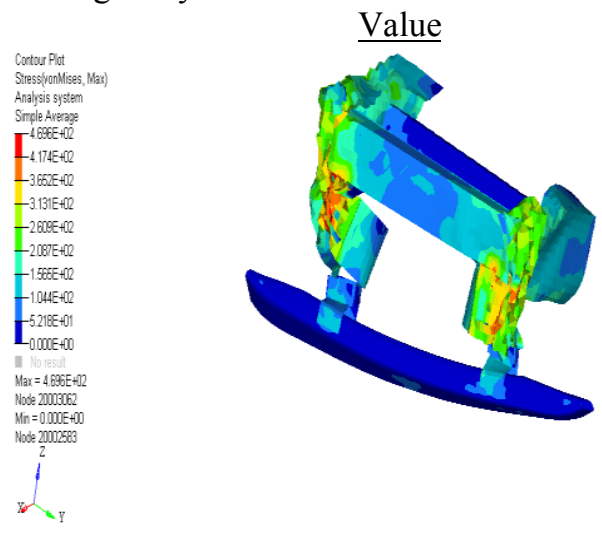

Displacement Value 

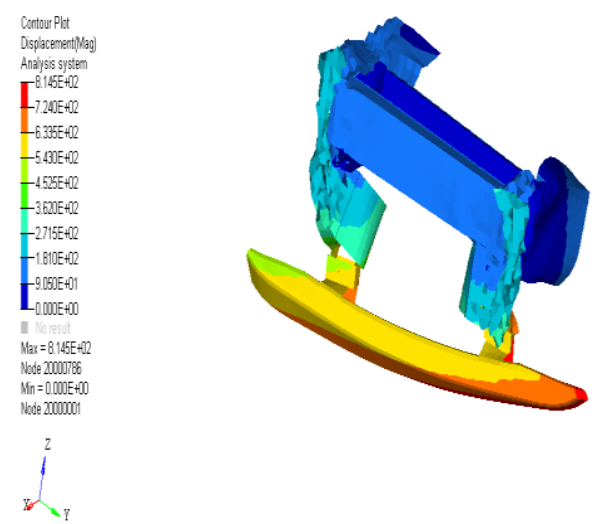

If we compare the Displacement \& Stress \& Strain Analysis Values of FUPD Model-1, These Values are Crossing the Maximum Yield point Values of Mild steel is 350-450MPa.From the above table the Maximum vonmisses stress Value is $814 \mathrm{MPa}$. So the first model is unsafe.

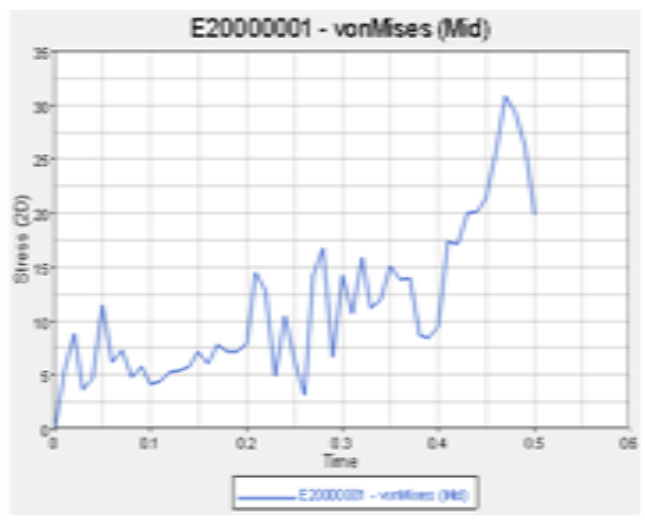

Vonmisses Stress vs. Time Graph

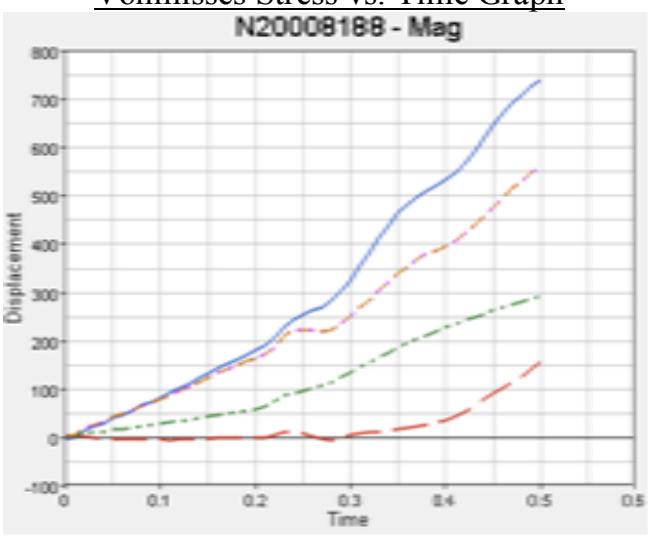

Displacement vs. Time Graph Model-2

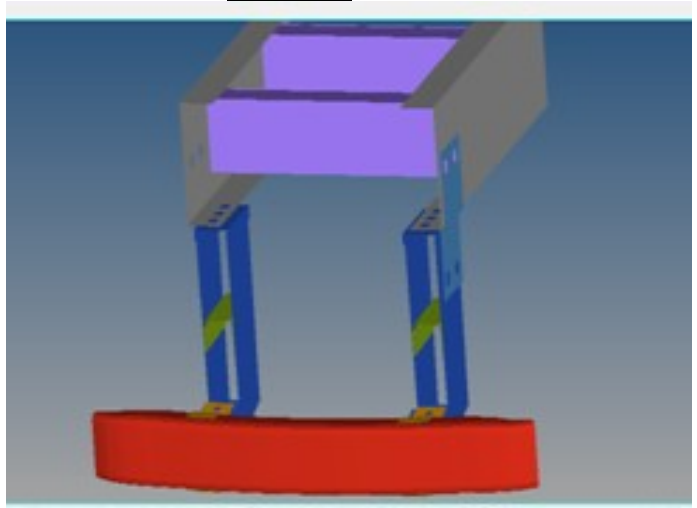


In this second model the plate is of thickness of $1 \mathrm{~mm}$ is attached to connect the surfaces of the stay bracket and doing analysis for the model.

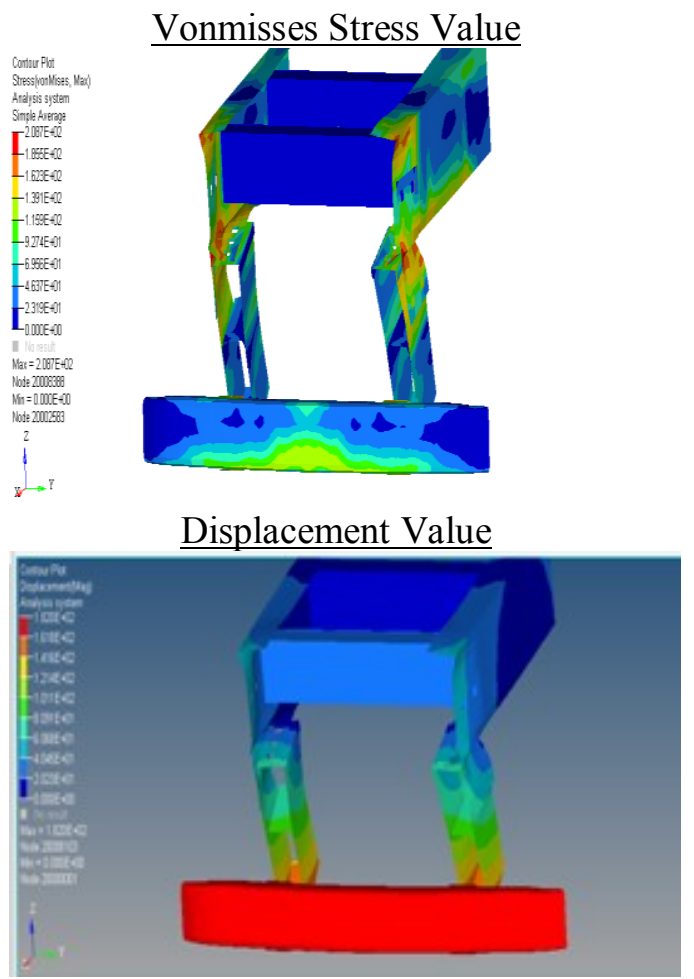

If we compare the Displacement \& Stress \& Strain Analysis Values of FUPD Model-2, These Values are within the Maximum yield point Values of Mild steel is 350-450MPa.From the above the Maximum stress Value is $182 \mathrm{MPa}$.So the model is safe for the implementation of FUPD to the heavy vehicles.

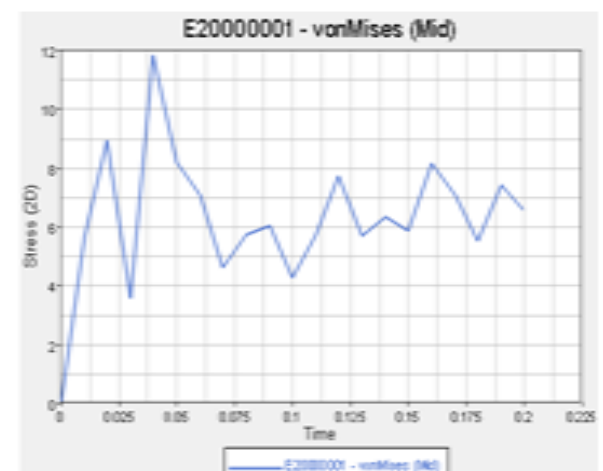

Vonmisses Stress vs. Time Graph

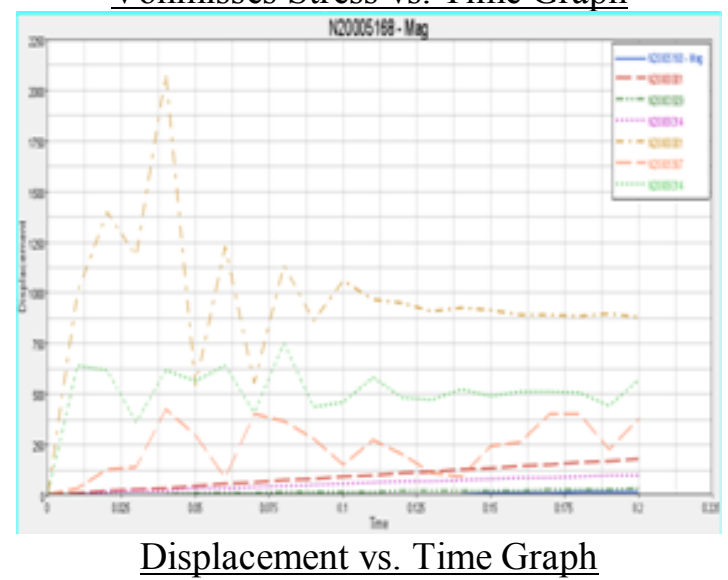




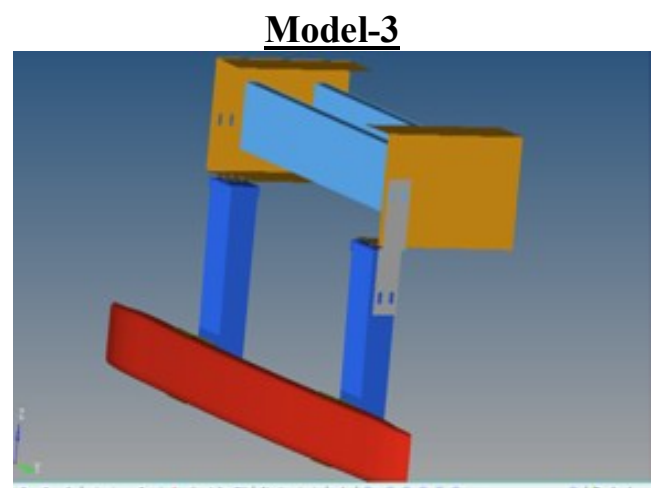

In this third model the plate is of thickness of $1 \mathrm{~mm}$ is attached to connect the surfaces of the stay bracket by closing front and back sides of the Fupd and doing analysis for the model.

Vonmisses Stress Value
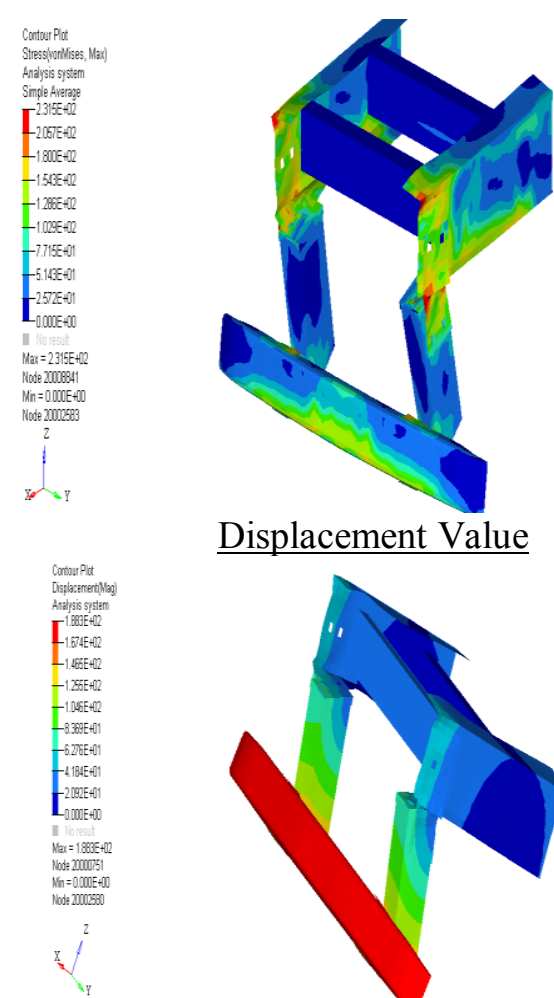

If we compare the Displacement \& Stress \& Strain Analysis Values of FUPD Model-3, These Values are within the Maximum yield point Values of Mild steel is 350-450MPa.From the above the Maximum stress Value is $188 \mathrm{MPa}$.But if we compare the model 2 and 3 values this value is slightly greater than 2nd model.

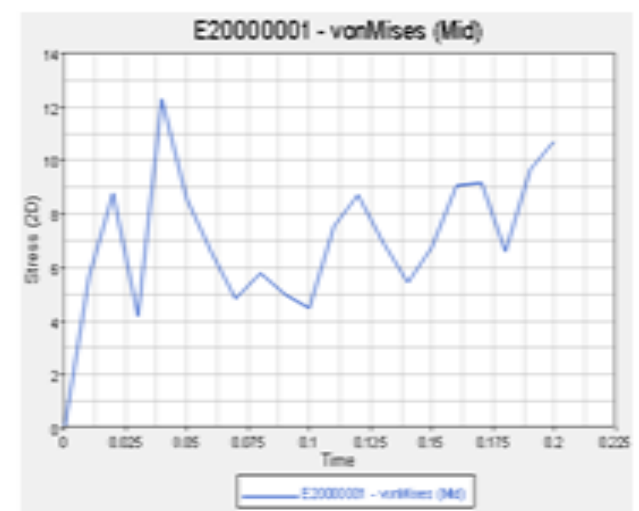

Vonmisses Stress vs. Time Graph 


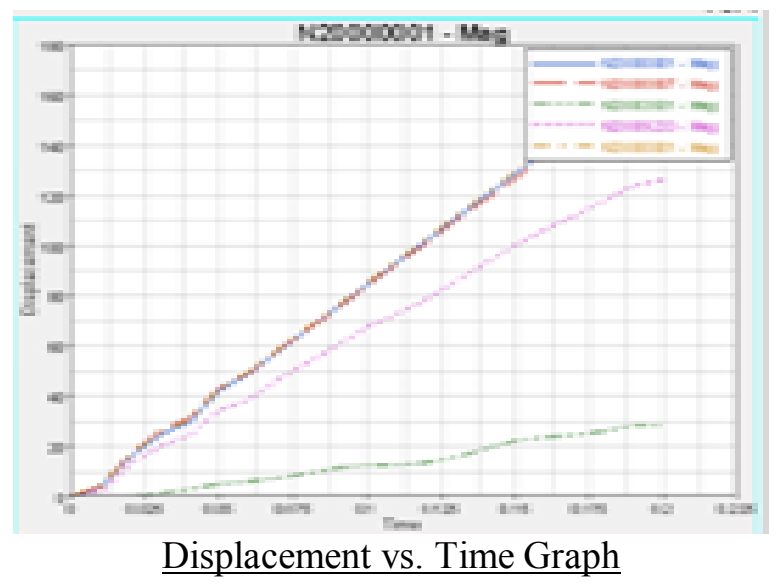

Comparison of Displacement Vs Time Graph for three
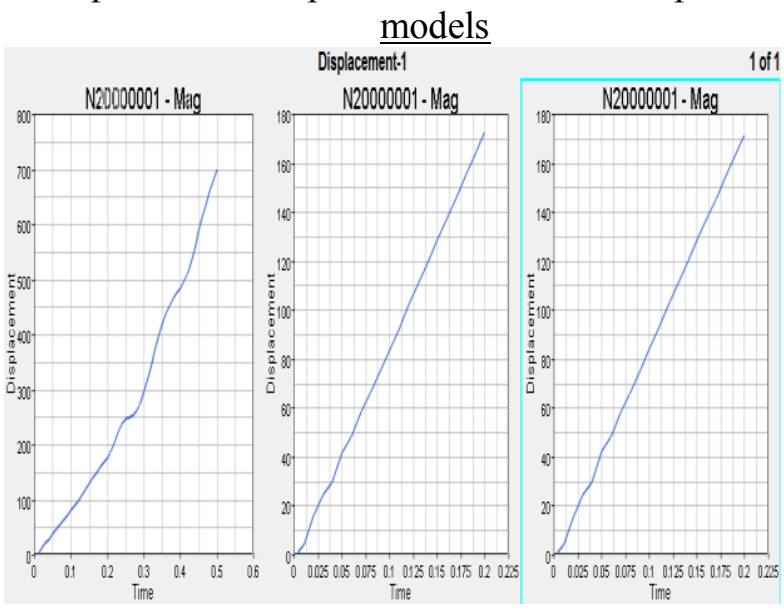

$10+1$

\begin{tabular}{|c|c|c|}
\hline \multicolumn{3}{|c|}{$\begin{array}{c}\text { COMPARISION OF FUPD VONMISES STRESS } \\
\text { VALUES FOR THREE MODELS }\end{array}$} \\
\hline MODEL-1 & MODEL-2 & MODEL-3 \\
\hline $4.696 \mathrm{E}+02$ & $2.087 \mathrm{E}+02$ & $2.315 \mathrm{E}+02$ \\
\hline $4.174 \mathrm{E}+02$ & $1.855 \mathrm{E}+02$ & $2.057 \mathrm{E}+02$ \\
\hline $3.662 \mathrm{E}+02$ & $1.623 \mathrm{E}+02$ & $1.800 \mathrm{E}+02$ \\
\hline $3.131 \mathrm{E}+02$ & $1.391 \mathrm{E}+02$ & $1.543 \mathrm{E}+02$ \\
\hline $2.609 \mathrm{E}+02$ & $1.159 \mathrm{E}+02$ & $1.286 \mathrm{E}+02$ \\
\hline $2.087 \mathrm{E}+02$ & $9.274 \mathrm{E}+02$ & $1.029 \mathrm{E}+02$ \\
\hline $1.566 \mathrm{E}+02$ & $6.956 \mathrm{E}+02$ & $7.715 \mathrm{E}+01$ \\
\hline $1.044 \mathrm{E}+02$ & $4.637 \mathrm{E}+02$ & $5.143 \mathrm{E}+01$ \\
\hline $5.218 \mathrm{E}+01$ & $2.319 \mathrm{E}+01$ & $2.572 \mathrm{E}+01$ \\
\hline $0.000 \mathrm{E}+00$ & $0.000 \mathrm{E}+01$ & $0.000 \mathrm{E}+00$ \\
\hline $\begin{array}{c}\mathrm{Max}= \\
4.696 \mathrm{E}+02\end{array}$ & $\begin{array}{c}\mathrm{Max}= \\
2.087 \mathrm{E}+02\end{array}$ & $\begin{array}{c}\operatorname{Max}= \\
2.315 \mathrm{E}+02\end{array}$ \\
\hline $\begin{array}{c}\text { Min }= \\
0.000 \mathrm{E}+00\end{array}$ & $\mathrm{Min}=0.000 \mathrm{E}+01$ & $\mathrm{Min}=0.000 \mathrm{E}+00$ \\
\hline
\end{tabular}

\begin{tabular}{|c|c|c|}
\hline \multicolumn{3}{|c|}{ COMPARISION OF FUPD DISPLACEMENT VALUES FOR } \\
THREE MODELS \\
\hline MODEL-1 & MODEL-2 & MODEL-3 \\
\hline $8.145 \mathrm{E}+02$ & $1.820 \mathrm{E}+02$ & $1.883 \mathrm{E}+02$ \\
\hline $7.240 \mathrm{E}+02$ & $1.618 \mathrm{E}+02$ & $1.674 \mathrm{E}+02$ \\
\hline $6.336 \mathrm{E}+02$ & $1.416 \mathrm{E}+02$ & $1.465 \mathrm{E}+02$ \\
\hline $4.525 \mathrm{E}+02$ & $1.214 \mathrm{E}+02$ & $1.255 \mathrm{E}+02$ \\
\hline $3.620 \mathrm{E}+02$ & $1.011 \mathrm{E}+02$ & $1.046 \mathrm{E}+02$ \\
\hline $1.810 \mathrm{E}+02$ & $8.091 \mathrm{E}+02$ & $8.369 \mathrm{E}+01$ \\
\hline $9.050 \mathrm{E}+01$ & $6.068 \mathrm{E}+01$ & $6.276 \mathrm{E}+01$ \\
\hline $0.000 \mathrm{E}+00$ & $4.045 \mathrm{E}+00$ & $4.184 \mathrm{E}+01$ \\
\hline Max $=8.145 \mathrm{E}+02$ & $2.023 \mathrm{E}+01$ & $2.092 \mathrm{E}+01$ \\
\cline { 2 - 3 } & $0.000 \mathrm{E}+01$ & $0.000 \mathrm{E}+00$ \\
\hline Min=0.000E +00 & Max $=1.820 \mathrm{E}+00$ & Max $=1.883 \mathrm{E}+00$ \\
\hline & Min $=0.000 \mathrm{E}+00$ & Min $=0.000 \mathrm{E}+00$ \\
\hline
\end{tabular}

From the above table, If we compare the displacement \& Stress Values of both the three models there is a high Value in Model-1 and Model-2\& Model-3 are low values. The Models-2\&3 are within the Yield Point Values of Mild Steel i.e. 350-450MPa.But Model-1 is crossing Maximum Yield Point value, so the Model-1 is failed.,Model-2 Stress \& Displacement value are less comparing with the Model-3.so FUPD Model-2 is suggested for implementing to the heavy vehicle.

\section{Conclusion}

1. Head on collision contribute significant amount of serious accidents due to lack of FUPD in heavy trucks.

2. As per Indian standard IS 14812:2005 regulation the Front Under-run Protection Device is designed using Nx8.0 software and analysed by commercial finite element software and found satisfactory results.

3. The maximum displacement, Von mises stresses and strains under impact load of FUPD bar in different cases are studied to meet the requirements as per IS 14812:2005, and this results are to be compared with experimental results.

4. With the above used CAE tools we can reduce the time and increase the productivity of the design and avoid the costly experimental testing.

5. As per above three results second model is safe, strength and low weight model.

6. We can suggest to automobile industries to keep this type of FUPD to car, gypsy, truck, busses...Etc. which saves the life of passenger with less injury.

\section{Reference}

[1]. EEVC Working Group 14. "Development of Test Procedure for Energy-absorbing Front Under run Protection Systems for Trucks". Report, December 1996.

[2]. FAEBER, E.;CESARI, D.; HOBBS, A.;HUIBERS, J.; KAMPEN, B.; PAEZ, J.; WYKES,N. "Improvement of Crash Compatibility Between Cars". 16th ESV Conference, Windsor. 1998.

[3]. MENDIS, K.; MANI, A.; PRASAD, A.K.; WILKE, D.; MONK, M.; ClARKE, R.M.."Concepts to Reduce Heavy Truck Aggressively in Truck-to-Car Collisions". 15th ESV Conference, Melbourne.1996.

[4]. Bjornstig J, Bjornstig Ulf, Eriksson A, "Passenger car collision fatalities - With special emphasis on collision with heavy vehicles", Accident Analysis and Prevention 2008, P 158-166. 
[5]. Cercarelli L.R., Lagge M., Lee A.H, Meuleners L.B., "Estimating crash involving heavy commercial vehicles in western Australia”, Accident Analysis and Prevention,1999-2000,P 170-174.

[6]. Leneman F J W, Schram R, Wismans J S H M, Zweep W J , “Assessment criteria for assessing energy absorbing Front Under-run Protection on Trucks", Eindhoven University of Technology, Netherlands, ICrash 2006

[7]. Coo P, Leneman F, Kellendonk G, “Assessment of Energy Absorbing Under-run Protection Device”, TNO Automoblie, Netherlands, 04

[8]. Hirase T, Kubota H, Sukhegawa Y, “Japan's Approach for Car to Truck Compatibility in Head-on Collisions”, 07-0989

[9]. John Ian S, "Energy Absorbing Structure for the Front of Heavy Trucks", IIHS, 1986, 0180R.

[10]. John L, Rechnitzer G, "Front Side and Rear Under-run Protection Device”, Accident Research Centre, Monash University, 2002, 194

[11]. Vehicle Standard (Indian Automotive Standard) for Rear Under-run Protection Device IS 14812 - 2005. 